\title{
Transcriptional Regulation of Nos2 via STAT5B Binding to Nos2 Gene Promoter Mediates Nitric Oxide Production: Relevance in $\boldsymbol{\beta}$-Cell Maintenance
}

\author{
Annu Josepha,b Lekshmy CR Nair ${ }^{a}$ Betcy Susan Johnson ${ }^{a, b} \quad$ Philip Litto Thomasa,b \\ Renjini Ambika Padmanabhan ${ }^{a}$ Neethu Puthumadathila Malini Laloraya ${ }^{a}$
}

aFemale Reproduction and Metabolic Syndromes Laboratory, Division of Molecular Reproduction,

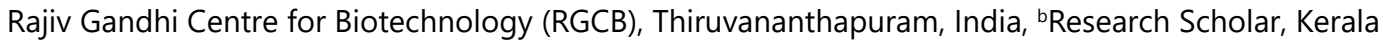
University, Senate House Campus, Palayam, Thiruvananthapuram, India

\section{Key Words}

Type 1 diabetes $\cdot$ STAT5B $\cdot$ Transcriptional regulation $\cdot$ NOS2 Nitric oxide $\cdot$ Hydrogen peroxide $\cdot$ Oxidative stress $\cdot$ Beta cell

\begin{abstract}
Background/Aims: Type 1 Diabetes (T1D) involves autoimmune attack due to reduced regulatory $T$ cells as an effect of mutant Stat $5 b(C 1462 A)$ in non-obese diabetic (NOD) mice, a T1D model resulting in pancreatic $\beta$-cell destruction. Although reactive oxygen species are considered to orchestrate the immune attack, the role of nitric oxide (-NO) still remains debatable. Since JAK-STAT pathway is known to induce Nos2, we investigated the role of STAT5B in nitric oxide generation and oxidative stress. Methods: In this study, we have used chromatin immunoprecipitation with STAT5B antibody to explore whether STAT5B binds Nos2 promoter. Using Stat5b gene silencing and overexpression models in MIN6 mouse pancreatic $\beta$-cell line we have assayed nitric oxide and its end products, superoxide levels, $\mathrm{H}_{2} \mathrm{O}_{2}$ levels, and expression of genes related to redox pathway by immunocytochemistry, biochemical assays, quantitative real time PCR and western blotting. Results: Our results prove that STAT5B binds to the candidate gamma-interferon-activated (GAS) element in Nos2 promoter thereby inducing Nos2 mRNA transcription resulting in NOS2 protein expression in MIN6, a mouse pancreatic $\beta$-cell line. Our findings are substantiated by reduced $\cdot \mathrm{NO}$ as well as nitric oxide end products (nitrate and nitrite), and increased superoxide production in Stat5b silenced MIN6 cells. Our results indicate that $C 1462 \mathrm{~A}$ mutant STAT5B shows lack of $\cdot \mathrm{NO}$ generation ability. To detoxify excess superoxide as a consequence of lowered Nos2, an overexpressed SOD2 in Stat5b silenced cells results in increased $\mathrm{H}_{2} \mathrm{O}_{2}$ production. $\mathrm{H}_{2} \mathrm{O}_{2}$ metabolizing enzymes do not show upregulation upon Stat5b silencing, and thus oxidative stress is brought about by amassed

L. CR Nair and B. S. Johnson contributed equally to this work.


$\mathrm{H}_{2} \mathrm{O}_{2}$. Stat5b silencing finally reduces AKT expression, a prosurvival signal. Conclusion: Our study enables us to conclude that $\beta$-cell stress is aggravated by the incapability of STAT5B to induce Nos 2 resulting in $\mathrm{H}_{2} \mathrm{O}_{2}$ accumulation and the ensuing oxidative stress enhances $\beta$-cell damage.

\section{Introduction}

Type 1 diabetes (T1D) is acknowledged to occur due to autoimmune mediated destruction of $\beta$-cells which secrete insulin [1]. The loss of $\beta$-cells has been ascribed to autoimmune attack as a consequence of 'insulitis', an inflammatory reaction due to infiltration by mononuclear cells [2]. The role of cytotoxic diabetogenic $\mathrm{CD}^{+}$and $\mathrm{CD} 4^{+}$cells [3] has been elucidated in the pathogenesis of T1D. Peripheral tolerance is compromised in T1D due to defective FOXP3(+)CD4(+) regulatory T cells (Tregs) frequency or due to reduced FOXP3 expression [4]. T1D management revolves around developing methods to improve Treg number and function [5]. Reduced Treg numbers are seen in patients with Stat5b deficiency [6]. STAT5B is the maestro of Treg generation as increased FOXP3 expression under IL2STAT5B axis is an important step in Treg generation, and this has a bearing on diabetes pathogenesis [7] since non obese diabetic (NOD) mice have a L327M mutant STAT5B with weaker DNA binding property [8].

It is important to note that STAT5 activity in $\beta$-cells affects susceptibility to experimentally-induced Type 1 and Type 2 diabetes [9]. Also, high levels of STAT5B protein compared to STAT5A are reported to be present in pancreatic $\beta$-cells [10] suggesting that STAT5B could have a direct role in $\beta$-cell fate. $\beta$-cell death is thought to be a consequence of oxidative stress since the intensity of autoimmune attack on $\beta$-cells is modulated by reactive oxygen species (ROS) which is critical to proinflammatory cytokine production, CD8+ T cell proliferation, CTL target lysis, and granzyme expression thereby regulating adaptive immune response [11]. Macrophage and T-cell generated superoxide in particular is essential for autoreactivity induction and T1D [12]. Macrophages infiltrate pancreatic $\beta$-cells and release ROS, superoxide and $\cdot \mathrm{NO}$, to cause extensive damage [13] showing a close nexus of ROS and adaptive immunity. Out of the three isoforms of NOS in pancreatic islets, nNOS (neuronal NOS, NOS1) and iNOS (inducible NOS, NOS2) identified in pancreatic $\beta$-cells and eNOS (endothelial NOS, NOS3) in islet endothelial cells [14] are engaged in ·NO production. Elevated $\cdot \mathrm{NO}$ production by $\beta$-cell specific Nos2 (iNOS) overexpression causes $\beta$-cell degeneration leading to insulin dependent diabetes [15]. T1D onset is associated with increased plasma $\mathrm{NO}$ [16]. High concentrations of proinflammatory cytokines (IL1 $\beta$, TNF $\alpha$ and IFN $\gamma$ ) which induce nitrite and cGMP accumulation by human islets inhibits insulin secretion but conversely low concentration stimulates insulin secretion [17]. Reports of reduced $\cdot \mathrm{NO}$ in Type 2 diabetes (T2D) [18] as well as association of NOS2 polymorphism with T2DM [19] further complicates the scenario about the role of $\mathrm{NO}$ in diabetes.

Since prolactin (PRL) signals through JAK-STAT5 pathway and induces several genes including inducible nitric oxide synthase (iNOS/NOS2) [20] and PRL receptors are expressed by pancreatic $\beta$-cells [21], we explored whether STAT5B could regulate NOS2 expression in $\beta$-cells. Thus we analyzed Nos2 promoter region for presence of STAT5B binding site, conducted chromatin immunoprecipitation (ChIP) experiments to prove that STAT5B can bind Nos2 promoter and assessed the levels of Nos2 in PRL-stimulated MIN6 pancreatic $\beta$-cell line. Fluorescent dyes as well as fluorescent probes have been successfully in use for detection of different ROS and reactive nitrogen species (RNS) in cells, with negligible side-products. Non-fluorescent 4-amino-5-methylamino-2',7'-difluorofluorescein diacetate (DAF-FM DA) forms a fluorescent product, which is comparatively photostable and specific, on reaction with $\cdot \mathrm{NO}$ [22]. MitoSOX Red is a commercially available fluorescent probe for 


\section{Cellular Physiology Cell Physiol Biochem 2018;52:141-155 \\ \begin{tabular}{ll|l} 
and Biochemistry & $\begin{array}{l}\text { DOl: 10.33594/000000010 } \\
\text { Published online: } 18 \text { February } 2019\end{array}$ & $\begin{array}{l}\text { C 2019 The Author(s). Published by } \\
\text { Cell Physiol Biochem Press GmbH\&Co. KG }\end{array}$ \\
\cline { 2 - 3 }
\end{tabular} \\ Joseph et al.: STAT5B Activates Nos2 and Reins Oxidative Stress}

detection of mitochondrial superoxide [23]. Since these tools are specific in the detection of their products, we have used them for our study. We also assessed the impact of Stat $5 b$ knockdown or mutant Stat5b transfected, on the other enzymes involved in ROS and RNS regulation instrumental in causing oxidative stress.

\section{Materials and Methods}

Cell line, constructs and reagents

MIN6 cell pancreatic $\beta$-cell line (obtained from NCCS, Pune) was routinely maintained in DMEM containing $25 \mathrm{mM}$ glucose supplemented with $15 \%$ FBS, $2 \mathrm{mM}$ L-Glutamine, $0.1 \mathrm{mM} \beta$-mercaptoethanol, $100 \mathrm{U} / \mathrm{mL}$ penicillin, and $100 \mu \mathrm{g} / \mathrm{mL}$ streptomycin. Medium was changed every 2 days and the cells were passaged when $80-85 \%$ confluent. All culture media and supplements were from Thermo Fisher Scientific, Waltham, MA, USA. Control siRNA (sc-37007) and Stat5b siRNA (sc-37011) were from Santa Cruz Biotechnology (SCBT), Dallas, TX, USA. Wild and mutant (C1462A mutation with weaker DNA binding ability) Stat5b constructs were made for transfection studies using pDsRed-Express-C1 vector (Clontech, Takara Bio, Japan). 500ng/mL PRL (Biovision Inc., San Francisco, USA) was used to stimulate Stat5b silenced/overexpressed MIN6 cells for 30 minutes. Anti-RNA polymerase II (ab5408, Abcam, Cambridge, UK) and anti-STAT5B (sc-1656X, SCBT, Dallas, TX, USA) were used in chromatin immunoprecipitation studies. Primary antibodies against actin (A2668, Sigma Aldrich, St. Louis USA), STAT5B (ab178941, Abcam, Cambridge, UK), and NOS2 (sc-651), SOD2 (sc-11407), catalase (sc-50508), AKT1/2/3 (sc-8312), BCL-xL (sc-7195) and ERK2 (sc-154) (SCBT, Dallas, TX, USA) were used for western blotting experiments.

\section{siRNA-mediated silencing of Stat5b in MIN6 cells}

The expression of Stat5b in MIN6 cells was silenced by transfection of siRNA targeting mouse Stat5b $(100 \mathrm{nM})$ in $40-50 \%$ confluent cells. The silencing was performed using Lipofectamine 3000 (Thermo Fisher Scientific, Waltham, MA, USA) reagent. Non-targeting control siRNA was used for control group. Lipofectamine-siRNA complex was added to each well and the plates were incubated at $37^{\circ} \mathrm{C}$ for 72 hours. It was further followed by $500 \mathrm{ng} / \mathrm{mL}$ PRL stimulation for 30 minutes, and the cells were trypsinized and collected.

Wild and C1462A mutant Stat5b transfection into MIN6 cell line

Transfection of wild and mutant (NOD) Stat5b-DsRed constructs was done in MIN6 cells at 90-95\% confluency in DMEM culture medium (composition detailed earlier). The constructs were transfected using Lipofectamine 3000 reagent and incubated for 48 hours followed by PRL stimulation. The cells were washed with PBS, fixed with $4 \%$ paraformaldehyde and observed under confocal microscope (Nikon, Tokyo, Japan).

\section{Chromatin immunoprecipitation}

Chromatin immunoprecipitation (ChIP) was done using EpiTect ChIP OneDay Kit (Qiagen, Hilden, Germany) according to the manufacturer's instructions. MIN6 cells were cultured in T25 flasks until 80\% confluency. The proteins were cross-linked to DNA using 1\% formaldehyde (Sigma-Aldrich, St. Louis, MO, USA) at $37^{\circ} \mathrm{C}$ for 10 minutes. The cells were then harvested and lysed using Lysis Buffer containing protease inhibitor cocktail and sonicated with Bioruptor ${ }^{\circledR}$ sonication device (Diagenode, Liege, Belgium) for the generation of chromatin fragments. The lysate was pelleted and supernatant pre-cleared with Protein A beads. Specific antibodies have to be used for the immunoprecipitation of chromatin fragments to which the protein of interest is bound. For this, precleared lysate was separated into three IP fractions, and incubated at $4^{\circ} \mathrm{C}$ overnight with mouse control IgG (Genei, Bangalore, India) as negative control, anti-RNA polymerase II as positive control or anti-STAT5B for the protein of interest. 1\% of IP fraction was kept as input fraction. Since RNA polymerase II is present at the promoters of all actively transcribed genes, it was used as the positive control. The IP fractions containing protein of interest bound to the corresponding chromatin region were immunoprecipitated with Protein A beads. Genomic DNA was isolated and purified, followed by RT-PCR using EpiTect ChIP qPCR Primer Assay for mouse Ccnd2, a known STAT5B target, and Nos2, the region under investigation (Qiagen, Hilden, Germany). 


\section{Cellular Physiology Cell Physiol Biochem 2018;52:141-155 \\ \begin{tabular}{ll|l}
\cline { 2 - 2 } DOl: 10.33594/000000010 & (c) 2019 The Author(s). Published by
\end{tabular} \\ and BiOChemistry Published online: 18 February 2019 Cell Physiol Biochem Press GmbH\&Co. KG \\ Joseph et al.: STAT5B Activates Nos2 and Reins Oxidative Stress}

\section{Simultaneous detection of $\cdot$ NO and superoxide by DAF-FM DA and MitoSOX Red}

MIN6 cells after 72 hours of siRNA transfection (Stat5b/Control) or 48 hours of wild Stat5b-DsRed/ C1462A mutant Stat5b-DsRed were washed, and the media replaced with phenol red-free DMEM containing $2 \mathrm{mM}$ L-glutamine and 10 $\mu$ M DAF-FM DA (D23842, Thermo Fisher Scientific, Waltham, MA, USA). After 30 minutes of incubation, cells were treated with 500ng/ml of PRL (Biovision Inc. USA) and further incubated at $37^{\circ} \mathrm{C}$ for 30 minutes. For siRNA treated samples, the cells were washed twice to remove excess probe and incubated with phenol red-free DMEM containing 5 $\mu$ M MitoSOX Red (M36008, Thermo Scientific) for 60 minutes. The cells were again rinsed with PBS and fixed with $4 \%$ PFA for 20 minutes at $4{ }^{\circ} \mathrm{C}$. This was followed by DAPI (4',6-diamidino-2-phenylindole) staining and imaging with Nikon AIR Confocal microscope using NIS Elements AR 4.00.04 software.

\section{Measurement of NOx end products}

The total NOx (nitrate + nitrite) and nitrite were measured using Nitrate/Nitrite colorimetric assay kit (Cayman Chemical, MI, USA). Nitrite was measured by addition of Griess reagent to $100 \mu \mathrm{L}$ sample directly. Since nitrate cannot be directly measured, it is converted to nitrite using nitrate reductase enzyme, followed by the addition of Griess Reagents. For total NOx assay, phenol-red free culture media used for growing MIN6 cells after treatment was analyzed. The samples and standards were added to each well of a 96well mictrotitre plate followed by nitrate reductase enzyme and cofactors according to the manufacturer's instructions. After incubation for 2 hours, Griess reagent was added. The final azo product was measured at 540nm on Tecan Infinite 200 (Tecan, Männedorf, Switzerland).

\section{Measurement of SOD activity}

SOD activity was measured using SOD determination kit (Sigma-Aldrich, St. Louis, USA) which utilizes the Dojindo's tetrazolium salt WST-1 (2-(4-Iodophenyl)-3-(4-nitrophenyl)-5-(2, 4-disulfophenyl)-2Htetrazolium, monosodium salt) to produce a water-soluble formazan dye upon reduction with superoxide anion. The rate of reduction is inhibited by SOD and the residual dye is measured by colorimetry. Briefly, MIN6 cells after treatment were collected and proteins extracted in a non-denaturing buffer (20mM Tris$\mathrm{HCl}, \mathrm{pH} 8.0,137 \mathrm{mM} \mathrm{NaCl}, 10 \%$ glycerol, 1\% NP-40, $2 \mathrm{mM}$ EDTA, protease inhibitor and phosphatase inhibitor cocktail (Sigma-Aldrich, St. Louis, USA)). Protein estimation was done and $25 \mu \mathrm{g}$ of each sample was used for the assay as per manufacturer's instruction. The plate was incubated for 20 minutes and absorbance read at 450nm on iMark Microplate reader (Bio-Rad, Hercules, CA, USA).

\section{Kinetics of $\mathrm{H}_{2} \mathrm{O}_{2}$ released from cells}

The kinetics of $\mathrm{H}_{2} \mathrm{O}_{2}$ released from cells was done using Amplex® Red (10-acetyl-3, 7-dihydroxyphenoxazine) hydrogen peroxide/peroxidase assay kit (Thermo Fisher Scientific, Waltham, MA, USA) as per the kit protocol with minor modifications. Briefly, spent medium was removed from the wells of 96-well culture plate after 72 hours of siRNA treatment and Krebs-Ringer phosphate (KRPG) buffer added to the cells. This was followed by $100 \mu \mathrm{L}$ of reaction mixture containing $50 \mu \mathrm{M}$ Amplex@ Red reagent and $0.1 \mathrm{U} / \mathrm{mL}$ HRP in KRPG. Amplex® Red reagent reacts with $\mathrm{H}_{2} \mathrm{O}_{2}$ to produce resorufin. Fluorescence (excitation at 530-560 $\mathrm{nm}$ and emission detection at 590 nm) was measured immediately, and subsequently measured every 30 minutes until 90 minutes on Tecan Infinite 200 (Tecan, Männedorf, Switzerland).

\section{MTT Assay}

For the assay, $10 \mu \mathrm{L}$ MTT reagent (TC-191, HiMedia Laboratories, India) was added to MIN6 cells in $90 \mu \mathrm{L}$ media without phenol red after 72 hours of siRNA treatment, to a final concentration of $0.5 \mu \mathrm{g} / \mu \mathrm{L}$, and incubated at $37^{\circ} \mathrm{C}$ for 2 hours under dark. After incubation, $100 \mu \mathrm{L}$ solubilisation buffer (prepared using $400 \mu \mathrm{L}$ of $1 \mathrm{M} \mathrm{HCl}, 10 \mathrm{~mL}$ Triton-X 100 and $90 \mathrm{~mL}$ isopropanol) was added and incubated at room temperature for 1 hour. Absorbance was read at 570nm.

\section{RNA isolation, cDNA synthesis, real time PCR}

Total RNA was isolated from MIN6 cells using miRNeasy Mini Kit (Qiagen, Hilden, Germany) according to the manufacturer's protocol and quantitated using ND-1000 spectrophotometer (Nanodrop Technologies, Thermo Fisher Scientific, Waltham, MA, USA). cDNA was prepared from 150ng RNA employing SuperScript VILO cDNA Synthesis kit (Thermo Fisher Scientific, Waltham, MA, USA) as per manufacturer's instructions. 


\section{Cellular Physiology Cell Physiol Biochem 2018;52:141-155 \\ \begin{tabular}{ll|l} 
and Biochemistry & $\begin{array}{l}\text { DOl: 10.33594/000000010 } \\
\text { Published online: } 18 \text { February } 2019\end{array}$ & $\begin{array}{l}\text { 2 2019 The Author(s). Published by } \\
\text { Cell Physiol Biochem Press GmbH\&Co. KG }\end{array}$ \\
\cline { 2 - 3 }
\end{tabular} \\ Joseph et al.: STAT5B Activates Nos2 and Reins Oxidative Stress}

qRT-PCR primers were designed using ABI Primer Express software. Power SYBR ${ }^{\circledR}$ Green PCR Master Mix (Thermo Fisher Scientific, Waltham, MA, USA) was used to perform quantitative real-time PCR in MicroAmp® Optical 384-Well Reaction Plates (Thermo Fisher Scientific, Waltham, MA, USA). PCR runs and fluorescence measurements were done in 7900 HT Fast Real Time PCR System (Thermo Fisher Scientific, Waltham, MA, USA) using standard cycling conditions. Relative expression levels were calculated using $\Delta \Delta \mathrm{Ct}$ method with 18SrRNA as the endogenous control.

\section{Preparation of total protein extracts}

The cells after treatment were collected by trypsinization and total protein extracted in protein extraction buffer containing 50mM Tris- $\mathrm{HCl}$ (pH 8.0), 150mM NaCl, 1\% NP-40, 0.5\% sodium deoxycholate, and $0.1 \%$ sodium dodecyl sulfate. Protein quantitation was performed using Lowry's method (DC Protein Assay kit, Bio-Rad, Hercules, CA, USA) on iMark Microplate reader (Bio-Rad, Hercules, CA, USA).

\section{SDS-PAGE and Western blot development}

The samples were run in SDS-PAGE and transferred onto a PVDF membrane (Bio-Rad, Hercules, CA, USA). The membrane was washed with PBST (pH 7.4, with $0.1 \%$ Tween 20 ), blocked with $3 \%$ gelatin or $5 \%$ BSA in PBST for 2 hours to prevent non-specific binding of antibodies. The membranes were then incubated with protein-specific primary antibody of varying dilutions overnight at $4^{\circ} \mathrm{C}$. The antibodies used were 1:3000 actin, 1:4000 STAT5B, 1:500 NOS2, 1:1000 SOD2, 1:500 catalase, 1:500 AKT1/2/3, 1:500 BCL$\mathrm{xL}$, and 1:100 ERK2. This was followed by incubation of the membrane with peroxidase-conjugated goat anti rabbit secondary antibody (Sigma-Aldrich, St. Louis, MO, USA). The blots were developed based on color reaction by enhanced chemiluminescence detection method (Clarity Western ECL Substrate; Bio-Rad, Hercules, CA, USA). The blots were imaged using VersaDoc Imaging System (Bio-Rad, Hercules, CA, USA).

\section{Statistical analysis}

Data are expressed as mean \pm SD and statistical analysis was performed by Student's $t$-test or one-way analysis of variance (ANOVA), as appropriate, using the statistical software Microsoft Excel and GraphPad Prism 5. P-values of $\leq 0.05$ were accepted as statistically significant.

\section{Results}

Identification of Nos2 as a STAT5B target in MIN6 cells

Both Nos2 and Stat5b genes are located on chromosome 11, as identified from their chromosome ideograms at the site UCSC Genome Browser on Mouse Dec. 2011 (GRCm38/ mm10) Assembly (http://genome.ucsc.edu/) (Fig. 1A) [24]. Nos2 promoter has a candidate gamma-interferon-activated (GAS) element, the known STAT5-binding site [25] and the binding site AGTTTCTTGGAAATC identified by ChampionChiP Transcription Factor Search Portal based on DECipherment Of DNA Elements (DECODE), proprietary database of SABiosciences, Qiagen is shown in Fig. 1B.

Since the presence of a binding site does not confirm actual binding of STAT5B to Nos2 promoter, we performed ChIP on PRL-stimulated MIN6 cells with STAT5B antibody. The qRTPCR of subsequently isolated STAT5B pulled-down genomic DNA showed amplification for Nos2, proving STAT5B binding to Nos2 promoter (Fig. 1C). Amplification of Ccnd2, a known target of STAT5B served as positive control. No detectable amount of DNA was amplified in DNA from IP fraction with mouse control IgG, thus eliminating the possibility of non-specific amplification.

\section{Stat5b knockdown MIN6 samples exhibit decreased Nos2 levels}

In order to assess the impact of Stat $5 b$ silencing on NOS promoter, MIN6 cells treated with $100 \mathrm{nM}$ of Stat5b siRNA or control siRNA for 72 hours were used for further studies. Significant knockdown of Stat $5 b(\mathrm{p}<0.008)$ was confirmed by analyzing its relative transcript levels, with 18SrRNA as the endogenous control (Fig. 1D). The real time transcript level expression of Nos 2 was found to reduce in Stat5b silenced MIN6 cells, with a fold change 


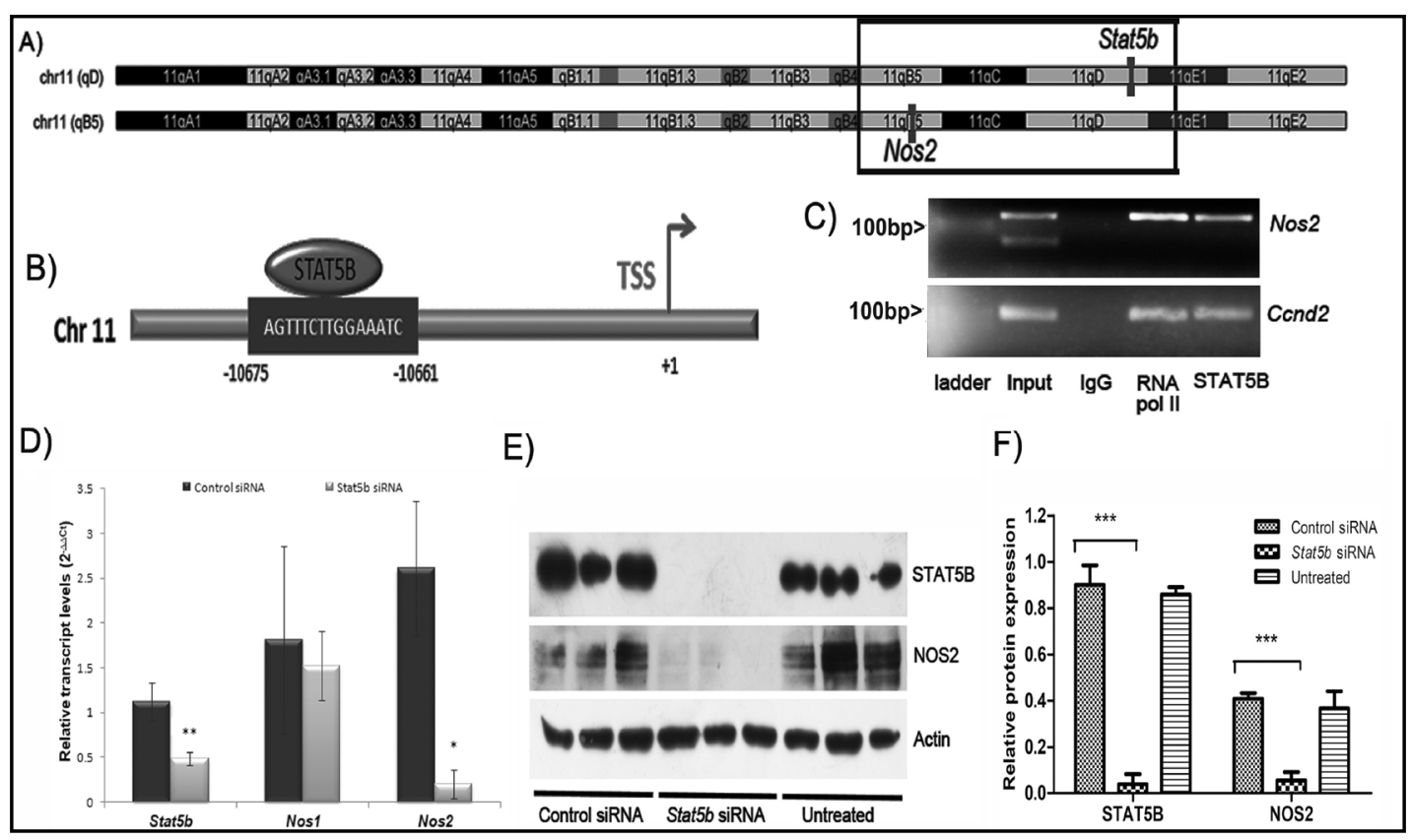

Fig. 1. STAT5B is a transcriptional regulator of Nos2. A) Chromosome ideogram of mouse Stat5b and Nos2 on chromosome 11(http://genome.ucsc.edu/). B) Cartoon representation of the putative binding site of STAT5B on Nos2 promoter, as identified from ChampionChiP Transcription Factor Search Portal (SABiosciences). C) Chromatin immunoprecipitation in MIN6 cells identified Nos2 as a direct target of STAT5B. Lane 1 - Input DNA, lane 2 - mouse control IgG, lane 3 - anti-RNA polymerase II antibody, lane 4 - anti-STAT5B antibody, lane 5 - DNA ladder. The image is a representation of experiment done thrice independently. D) Bar graph representation of $2^{-\Delta \Delta C t}$ of Stat5b and Nos2 transcripts showing downregulation in prolactin-induced Stat5b siRNA treated versus control siRNA treated MIN6 cells, calculated with respect to untreated cells and 18SrRNA as the endogenous control. $(n=3)$. E) Western blots and F) densitometric analysis of STAT5B and NOS2, showing a downregulation in PRL-induced siRNA treated samples, with actin as the loading control $(n=3)$. P-value was calculated using Student's t-test.

of 6.813 down regulation ( $\mathrm{p}<0.01$ ) (Fig. 1D) with no significant change in Nos1 levels, thus confirming the ChIP results. Stat5 $b$ siRNA-treated samples showed a highly significant decrease in immunopositive band intensity in STAT5B $(\mathrm{p}<0.001)$ and NOS2 $(\mathrm{p}<0.001)$ proteins on western blots with actin as loading control (Fig. 1E) corroborating our real time data. Graphical representation is shown in Fig. 1F after normalization with actin. Since untreated samples showed STAT5B and NOS2 expression similar to control siRNA treated samples, further experiments were performed on control versus Stat5b siRNA treated MIN6 cells.

\section{-NO production is regulated by STAT5B levels in MIN6 cells}

Techniques for simultaneous detection of $\mathrm{NO}$ and superoxide without interference have been previously reported [22]. Non-fluorescent DAF-FM DA detects NO by forming fluorescent benzotriazole on reaction with $\mathrm{NO}$ which is excited at $495 \mathrm{~nm}$ [26]. MitoSOX Red is a fluorogenic dye which selectively gets oxidised by mitochondrial superoxide and emits red fluorescence. Reduced green fluorescence and increased red fluorescence was detected by confocal imaging in PRL stimulated Stat $5 b$ knock down cells compared to PRL stimulated control siRNA treated cells or untreated cells suggesting decreased $\mathrm{NO}$ and increased superoxide in Stat5b knock down cells (Fig. 2A). 


\section{Cellular Physiology and Biochemistry}

Fig. 2. Stat5b silencing inhibits $\cdot$ NO production. A) Confocal imaging of nitric oxide accumulation in control, Stat5b siRNA treated and untreated MIN6 cells using DAFFM DA. After 72 hours siRNA transfection, cells were treated with $10 \mu \mathrm{M}$ DAF-FM DA for 30 minutes followed by treatment with PRL, incubated for further 30 minutes, washed with PBS, incubated with $5 \mu \mathrm{M}$ MitoSOX Red for 60 minutes, stained with DAPI and imaged at $358 \mathrm{~nm}$, $495 \mathrm{~nm}$ and $510 \mathrm{~nm}$ excitation. B) \& C) Representation of the concentration of total nitric oxide end products (nitrate + nitrite) and nitrite released from Stat5b siRNA treated versus control siRNA treated MIN6 cells, respectively. P-value was calculated using Student's t-test on GraphPad Prism 5.0 software $(n=3)$.

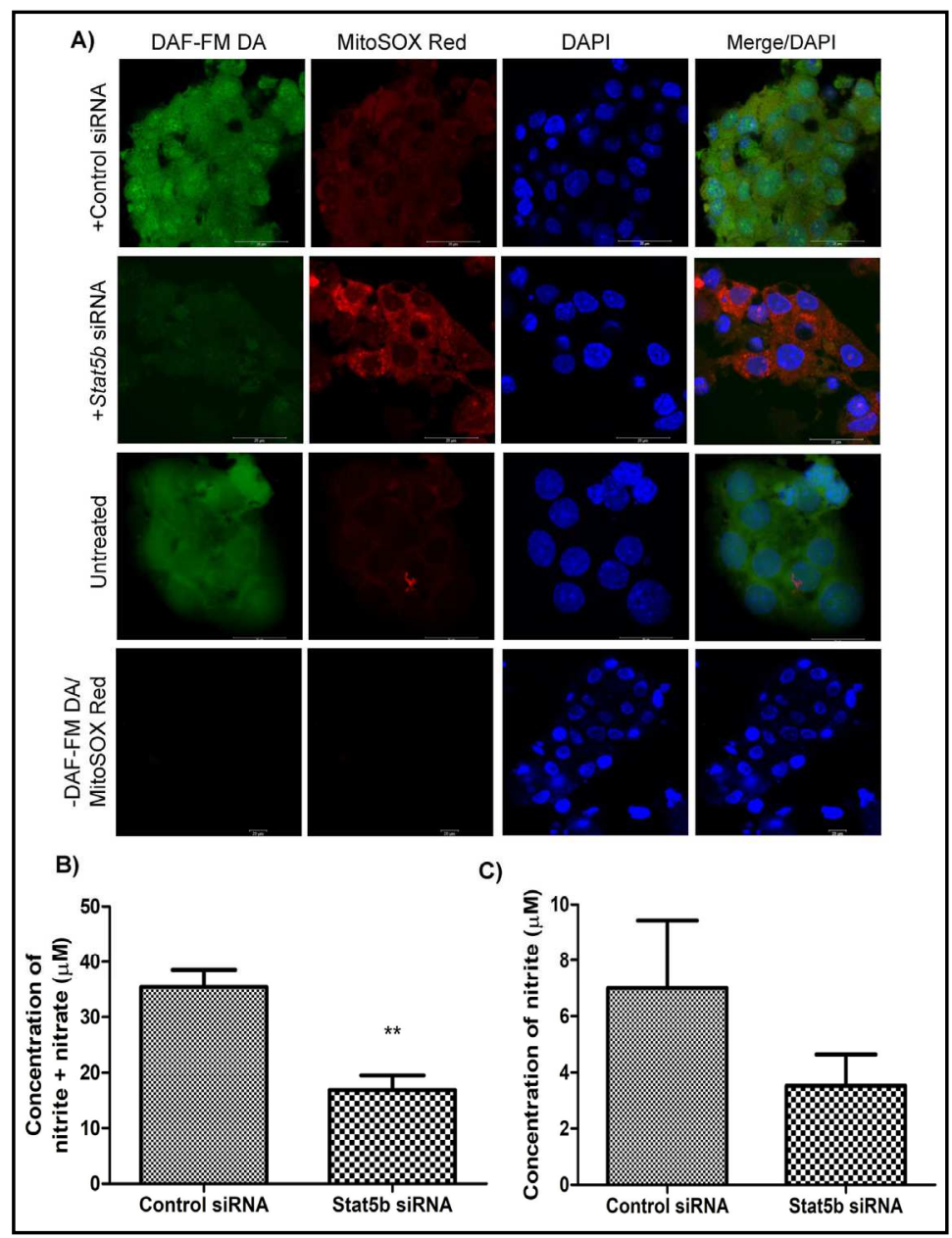

-NO end products are diminished in Stat5b siRNA treated samples

Since our confocal results indicated a decrease in $\cdot$ NO levels in cells with reduced STAT5B (Fig. 2A), we analyzed the release of - NO end products (nitrate and nitrite) in MIN6 cells. The total nitrate plus nitrite levels were found to be significantly lower in Stat5b knockdown samples at $16.88 \pm 2.652 \mu \mathrm{M}$, compared to control siRNA-treated samples at $35.42 \pm 3.146 \mu \mathrm{M}$ ( $\mathrm{n}=3$ in all groups, $\mathrm{p}=0.0065$ ) (Fig. $2 \mathrm{~B}$ ). Nitrite levels were also correspondingly reduced in the Stat $5 b$ siRNA treated samples at $3.533 \pm 1.102 \mu \mathrm{M}$ compared to the control samples at $7.000 \pm 2.433 \mu \mathrm{M}(\mathrm{n}=3)$ (Fig. $2 \mathrm{C})$.

\section{C1462A(L327M) mutant Stat5b is incapable of activating Nos2 promoter}

The effect of STAT5B overexpression on -NO levels was checked by confocal microscopy on transfecting MIN6 cells with wild-type and C1462A mutant Stat5b in DsRed vector followed by PRL stimulation. The cells transfected with wild-type Stat $5 b$ showed a substantial increase in NO levels, as observed by the increased fluorescence of DAF-FM DA, while mutant STAT5B-transfected cells did not show any variation compared to empty vector-transfected and non-transfected cells (Fig. 3), due to the inability of the mutant STAT5B to bind strongly to Nos2 promoter.

\section{Differential SOD2 expression in Stat5b siRNA treated MIN6 cells}

Lowered NO levels in condition with nonfunctional STAT5B could result in superoxide accumulation since -NO would not be available to react with it. Hence we studied the downstream events as a consequence of this reduced $\cdot \mathrm{NO}$. Superoxide anion $\left(\mathrm{O}_{2} \cdot{ }^{-}\right)$metabolizing 


\section{Cellular Physiology and Biochemistry

Fig. 3. C1462A(L327M) mutant Stat5b is unable to generate $\cdot$ NO. Confocal imaging of nitric oxide accumulation in wild and mutant Stat5b-DsRed plasmid transfected MIN6 cells using DAF-FM DA. Increased nitric oxide levels were found on overexpression of STAT5B (wStat5b-DsRed) while no significant change was observed in mutant STAT5B (mStat5bDsRed) with weaker DNA binding ability, compared to empty vector transfected and untransfected cells. The cells were treated with $10 \mu \mathrm{M}$ DAF-FM DA for 30 minutes followed by treatment with PRL, incubated for further 30 minutes, and imaged at $358 \mathrm{~nm}, 488 \mathrm{~nm}$ and $568 \mathrm{~nm}$ excitation. Nuclei were stained with DAPI.

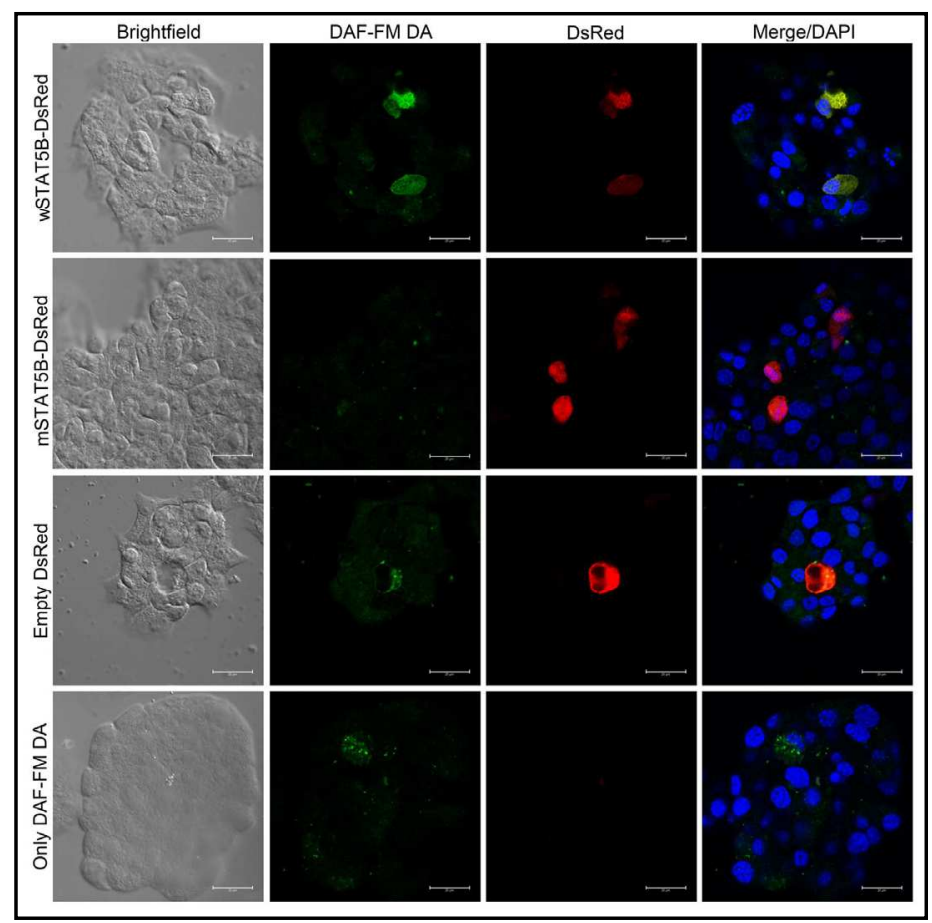

Fig. 4. Impact of Stat5b silencing on SOD2 and $\mathrm{H}_{2} \mathrm{O}_{2}$. A) Bar graph representation of increased relative transcript levels (2 $\Delta \Delta \mathrm{Ct}$ ) of Sod1, Sod2 and Sod3 in PRL induced Stat5b siRNA treated MIN6 cells versus control samples, with 18SrRNA as endogenous control (n = 3). B) Western blot and C) densitometric analysis of SOD2 denoting an increase in protein levels in Stat $5 b$ siRNA treated samples $(\mathrm{n}=3)$. The bands were

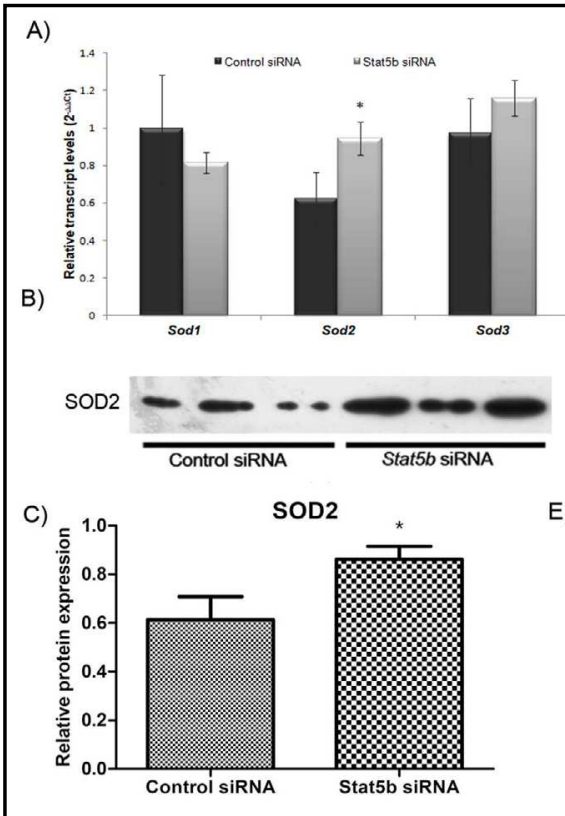

D) normalized using actin

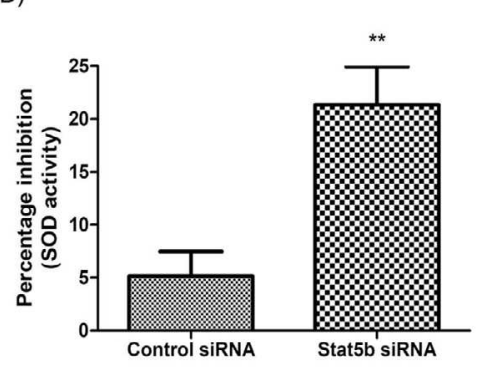

in Fig. 1E. D) Bar graph represents the effect of Stat5b siRNA treatment on percentage inhibition activity of SOD on WST-1, showing an increase in SOD activity in Stat5b siRNA treated samples (n = 3). P-value was calculated using Student's t-test on GraphPad Prism 5.0 software. E) Representation of detection of $\mathrm{H}_{2} \mathrm{O}_{2}$ released from cultured MIN6 cells treated with Stat5b siRNA versus control siRNA over a period of 0 to 90 minutes. The values show mean and SD of fluorescence from 3 replicates and indicates higher amounts of $\mathrm{H}_{2} \mathrm{O}_{2}$ released from $S t a t 5 b$ knockdown samples. 
Sod1, Sod2 and Sod3 transcripts were analyzed in Stat $5 b$ siRNA treated versus control siRNA treated MIN6 cells by qRT-PCR. The relative transcript levels of Sod1 and Sod3 did not show significant variation between control and Stat5b knockdown samples (Fig. 4A) while the relative expression of Sod2, the mitochondrial form of SOD, showed 2.06 fold upregulation (p $=0.023$ ) in Stat5b knockdown samples (Fig. 4A). This difference in SOD2 was corroborated in our western blot data $(\mathrm{p}=0.017)$ (Fig. 4B-C).

\section{Increased SOD activity is evident in Stat5b silenced MIN6 cells}

To assess whether the change in SOD2 expression is reflected in its enzymic activity, the inhibition activity of total SOD on WST-1 to produce a water soluble formazan dye was measured. The percentage inhibition activity of SOD was found to be $5.167 \% \pm 2.309$ in control and $21.33 \% \pm 3.617$ in Stat $5 b$ silenced samples with respect to untreated samples (n $=3$ in each group, $\mathrm{p}=0.0028$ ) (Fig. 4D).

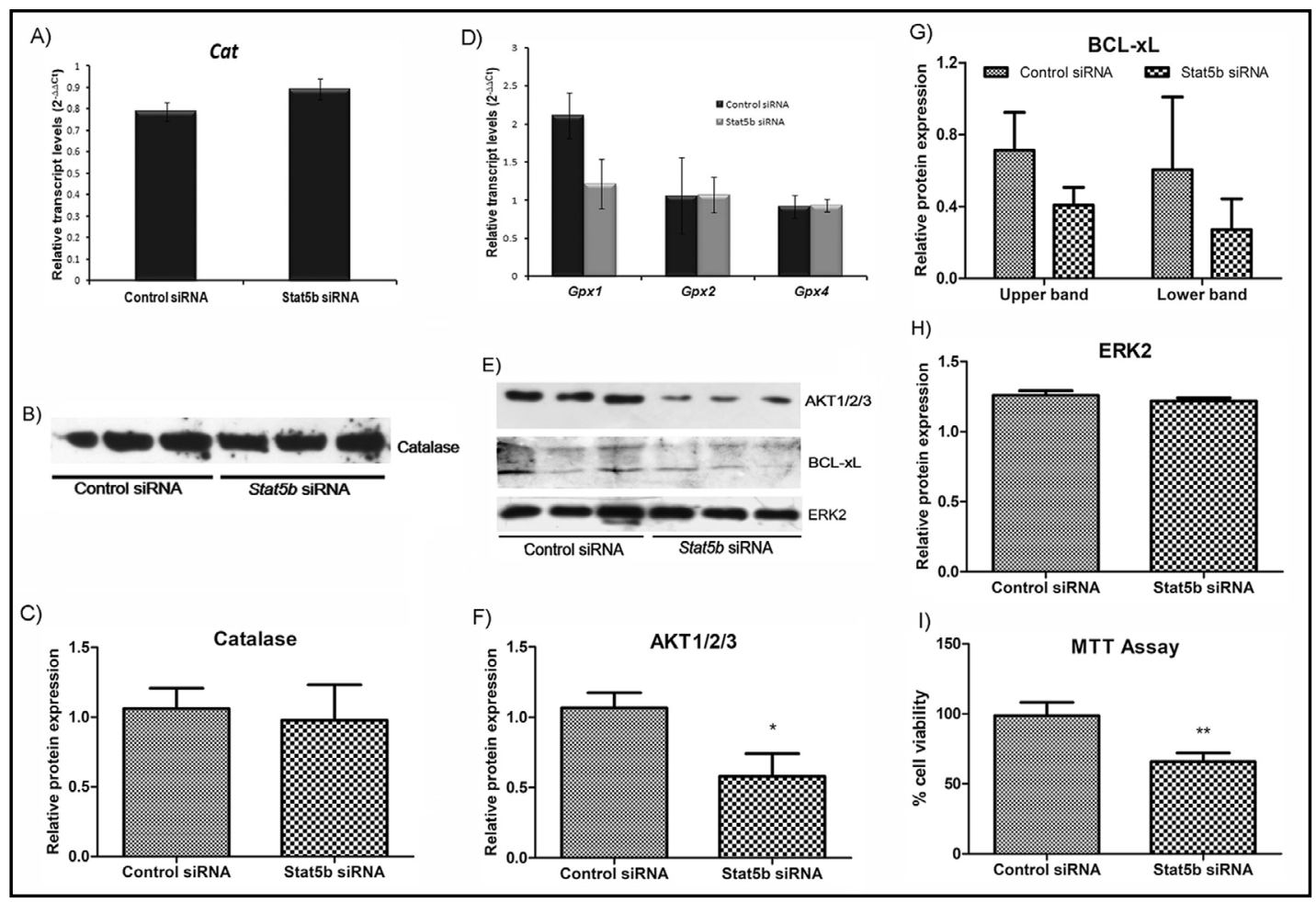

Fig. 5. Status of $\mathrm{H}_{2} \mathrm{O}_{2}$ metabolizing enzymes and AKT upon Stat5b silencing. A) qRT-PCR graphs showing the relative expression of $\mathrm{H}_{2} \mathrm{O}_{2}$ metabolizing enzyme Cat in control and Stat5b siRNA treated MIN6 cells with 18SrRNA as endogenous control. The transcript levels do not show significant difference between control and treated samples $(\mathrm{n}=3)$. B) Western blot and C) densitometric analysis of catalase $(\mathrm{n}=3)$ corroborate the Cat qRT-PCR results. D) qRT-PCR graphs showing the relative expression of $\mathrm{H}_{2} \mathrm{O}_{2}$ metabolizing enzymes Gpx1, Gpx2 and Gpx4 in control and Stat5b siRNA treated MIN6 cells with 18SrRNA as endogenous control $(\mathrm{n}=3)$. Except for $G p x 1$, the transcript levels do not show significant difference between control and treated samples. E) Western blot of prosurvival molecules AKT1/2/3, BCL-xL and ERK2. AKT1/2/3 and BCL-xL shows decreased levels in Stat5b siRNA treated samples compared to control siRNA treated samples, also represented by densitometric analysis of the bands (F and G), while ERK2 $(\mathrm{H})$ did not show significant difference $(\mathrm{n}=3)$. The bands were normalized using actin in Fig. 1E. I) Representation of percentage viability of control and Stat $5 b$ siRNA treated cells, as identified by MTT assay. Stat5b siRNA treated cells show decreased cell viability compared to the control siRNA treated cells $(n=3)$. 
Kinetics of $\mathrm{H}_{2} \mathrm{O}_{2}$ released show an increase in Stat5b siRNA treated cells

$\mathrm{H}_{2} \mathrm{O}_{2}$ levels were measured using Amplex Red reagent and HRP, and the fluorescence was measured every 30 minutes for 90 minutes. The kinetics of $\mathrm{H}_{2} \mathrm{O}_{2}$ released from the cells showed a substantial increase in fluorescence in $S t a t 5 b$ knockdown samples compared to control samples, indicating that the treatment has caused an increase in $\mathrm{H}_{2} \mathrm{O}_{2}$ levels after $S t a t 5 b$ knockdown (Fig. 4E) thus reiterating that SOD2 overexpression in Stat5b silenced cells translates to increased $\mathrm{H}_{2} \mathrm{O}_{2}$ production.

No increase in $\mathrm{H}_{2} \mathrm{O}_{2}$ metabolizing enzymes in Stat5b silenced cells

Real time transcript levels (Fig. 5A), as well as western blot (Fig. 5B-C) of the primary $\mathrm{H}_{2} \mathrm{O}_{2}$ detoxification enzyme catalase (CAT) did not show a significant difference between control and Stat $5 b$ siRNA treated MIN6 cell samples. The same was reflected in the transcript levels of Gpx2 and Gpx4, while the transcript levels of mitochondrial Gpx1 showed a fold change reduction of $0.58(p=0.024)$ (Fig. 5D), indicating that the enzymes present in the $\beta$-cells are not enough for the conversion of excess $\mathrm{H}_{2} \mathrm{O}_{2}$ produced to harmless $\mathrm{O}_{2}$, leading to its accumulation and induction of cellular stress.

\section{Stat5b silencing affects cell viability and prosurvival signals}

Since our data shows that STAT5B controls $\cdot \mathrm{NO}$ and superoxide production, we wanted to see whether it affects cell viability. The yellow tetrazolium dye 3-(4, 5-dimethylthiazol-2yl)-2, 5-diphenyltetrazolium bromide (MTT) is converted to purple formazan in the presence of cellular oxidoreductase enzymes present in viable cells. This product is then solubilised using acidified isopropanol to form a coloured solution the absorbance of which can then be read at $570 \mathrm{~nm}$. Percentage cell viability was calculated after experiment using the formula (Absorbance of control or Stat $5 b$ siRNA treated sample/ Absorbance of untreated sample) $* 100$. Control siRNA treated cells showed $98.65 \% \pm 9.54$ viability while viability of Stat $5 b$ knockdown cells decreased to $65.78 \% \pm 6.31(\mathrm{n}=3$ in all groups, $\mathrm{p}=0.0076)$ [Fig. 5, I] . This prompted us to look at the pro-survival pathway molecules. Upon Stat $5 b$ silencing a significant down-regulation was seen in AKT (p<0.01) (Fig. 5, E-F) and a reduction in BCL-xL (Fig. 5, E,G) while no change was seen in ERK2 levels (Fig. 5, E, H). Thus our results indicate that molecules regulating pro-survival pathway which are known to be under NO regulation are controlled by STAT5B.

\section{Discussion}

Dysregulation of STAT5B, located near the Idd4 Type 1 diabetes susceptibility interval, has been suggested to be involved in susceptibility to diabetes $[8,9]$. Our work clearly establishes that STAT5B is a transcriptional regulator of Nos2 (iNOS). It is known that cytokines like IFN- $\gamma$ promotes Nos2 transcription via interferon response factor (IRF1) [27], and PRL also behaves like a cytokine inducing Nos2 expression through JAK-STAT pathway [28]. Although presence of a candidate gamma-interferon-activated (GAS) element which is the known STAT5-binding site had been reported much earlier in the Nos2 promoter and -NO production modulated by STAT $1 \alpha$ binding to GAS element under bacterial lipopolysaccharide (LPS) and interferon (IFN)-gamma stimulation [25], our study for the first time to our knowledge proved a direct STAT5B binding to Nos2 promoter and regulating NO production. In our study Nos2, a putative target of STAT5B, was proved to be a bona fide target by CHIP experiments which showed that STAT5B binds to Nos2 promoter (Fig. 1C). Our finding of down regulation of Nos2 expression (Fig. 1D-F) and corresponding decreased levels of NO and its products nitrate and nitrite, and elevated superoxide levels in Stat5b knockdown MIN6 cells, reiterate that NO production is under STAT5B control (Fig. 2). Since Nos2 has been found to be a direct target of STAT5B and C1462A(L327M) mutant STAT5B has a weaker DNA binding ability in non obese diabetic mouse (NOD) compared to the wild-type [7], we looked at the effect of STAT5B overexpression on $\cdot \mathrm{NO}$ levels. Thus, further authentication 
comes from the lack of NO production in C1462A (L327M) mutant Stat5b transfected $\beta$-cells in contrast to increased NO generation in wild type $S t a t 5 b$ transfected $\beta$-cells (Fig. 3).

$\beta$-cell destruction in T1D is thought to be due to the inability to generate regulatory T-cell because of the incapability to induce FOXP3 expression as a consequence of defective STAT5B $[6,7]$. NO has been shown to be involved in immune response [29] especially in induction of CD4+CD25+ Foxp3 regulatory T cells christened NO-Tregs [30]. Thus our finding of a direct regulation of Nos2 transcription by STAT5B would potentiate the failure to generate Tregs in cases where Stat5b is defective. Our finding gains strength from the reports of association of lowered $\cdot$ NO production in type 2 diabetes and diabetic nephropathy [18, $31]$ as well as increased $\beta$-cell apoptosis in iNOS (-/-) mice [32]. It also appears that NO production would represent an autoregulatory loop for STAT5B activation as NOS2 and 'NO are known to augment IL-2 production [33, 34].

During oxidative metabolism, 0.4 to $4 \%$ of the oxygen gets converted to superoxide anion. NO can interact with superoxide radicals forming peroxynitrite, and is the only known biological molecule which can prevail over superoxide dismutase (SOD) for taking up superoxide under pathological conditions [35]. Due to decreased STAT5B activation on account of $S t a t 5 b$ silencing, $\beta$-cells have reduced Nos 2 expression which causes decreased $\cdot$ NO and its end products in our data which would result in more amounts of superoxide radicals available for SOD to convert to hydrogen peroxide $\left(\mathrm{H}_{2} \mathrm{O}_{2}\right)$. Since only the mitochondrial SOD2 is upregulated in our study while SOD1 and SOD3 remain unchanged (Fig. 4A-C), we postulate that the surge in $\mathrm{O}_{2}$ radicals is contained in the mitochondria itself by enhanced SOD2 activity leading to increased $\mathrm{H}_{2} \mathrm{O}_{2}$ in Stat5b silenced MIN6 $\beta$-cells (Fig. 4E).

Pancreatic $\beta$-cells are also highly susceptible to oxidative stress as antioxidant enzymes, CAT) and glutathione peroxidase (GPX), the enzymes responsible for deactivating $\mathrm{H}_{2} \mathrm{O}_{2}$ to oxygen and water, are considerably less in pancreatic islets compared to other tissues (only $5 \%$ of liver), and hence islets are more sensitive to cellular damage [36]. Of further concern is that pancreatic $\beta$-cells are incapable of upregulating the antioxidant enzymes during cellular stress and over-expression of catalase can help them combat $\mathrm{H}_{2} \mathrm{O}_{2}$ induced toxicity [37]. This inapt adaptation is also seen in our data where no corresponding increase occurs in $\mathrm{H}_{2} \mathrm{O}_{2}$ metabolizing enzymes, catalase and GPX isoforms, on Stat5b silencing. On the contrary, the situation is worsened by decreased Gpx1 mRNA expression upon Stat5b silencing (Fig. 5AD). An overactive Sod2 coupled to a repressed Gpx1 would result in excessive mitochondrial $\mathrm{H}_{2} \mathrm{O}_{2}$ levels which would result in oxidative stress resulting in $\beta$-cell destruction. The resulting oxidative stress further would inactivate STAT5 as reported earlier [38] thus setting off another regulatory route and block STAT5B mediated Nos2 induction. Thus it appears that increased oxidative stress coupled to decreased-NO bioavailability affects $\beta$-cell survival.

PRL is also known to promote $\beta$-cell survival by increasing the expression of antiapoptotic protein BCL-xL via JAK2/STAT5 pathway [39]. PRL mediated STAT5 activation is also shown to regulate AKT1 expression by binding to a unique promoter in Akt1 and propagating survival signals and evading apoptosis [40]. $\mathrm{NO}$ on the other hand is known to attenuate phosphatidylinositol 3-kinase (PI3K)/Akt survival pathway in insulin-producing RINm5F cells [41] and has been reported to be involved in AKT activation [42]. Thus our results of STAT5B boosting.NO production by binding to Nos2 promoter enable us to postulate that STAT5B transcriptionally activates Nos2 and maintains AKT and BCL-xL levels (Fig. $5 \mathrm{E}-\mathrm{H}$ ), thereby functioning as a major regulator of $\beta$-cell maintenance, also indicated by the reduced viability in Stat5b knockdown cells (Fig. 5I). This is further strengthened by the recent report of differentiation of stem cells into functional $\beta$-cells by·NO induced epigenetic modification of PDX1 (Pancreatic and duodenal homeobox 1) important for pancreatic development during embryogenesis [43]. 


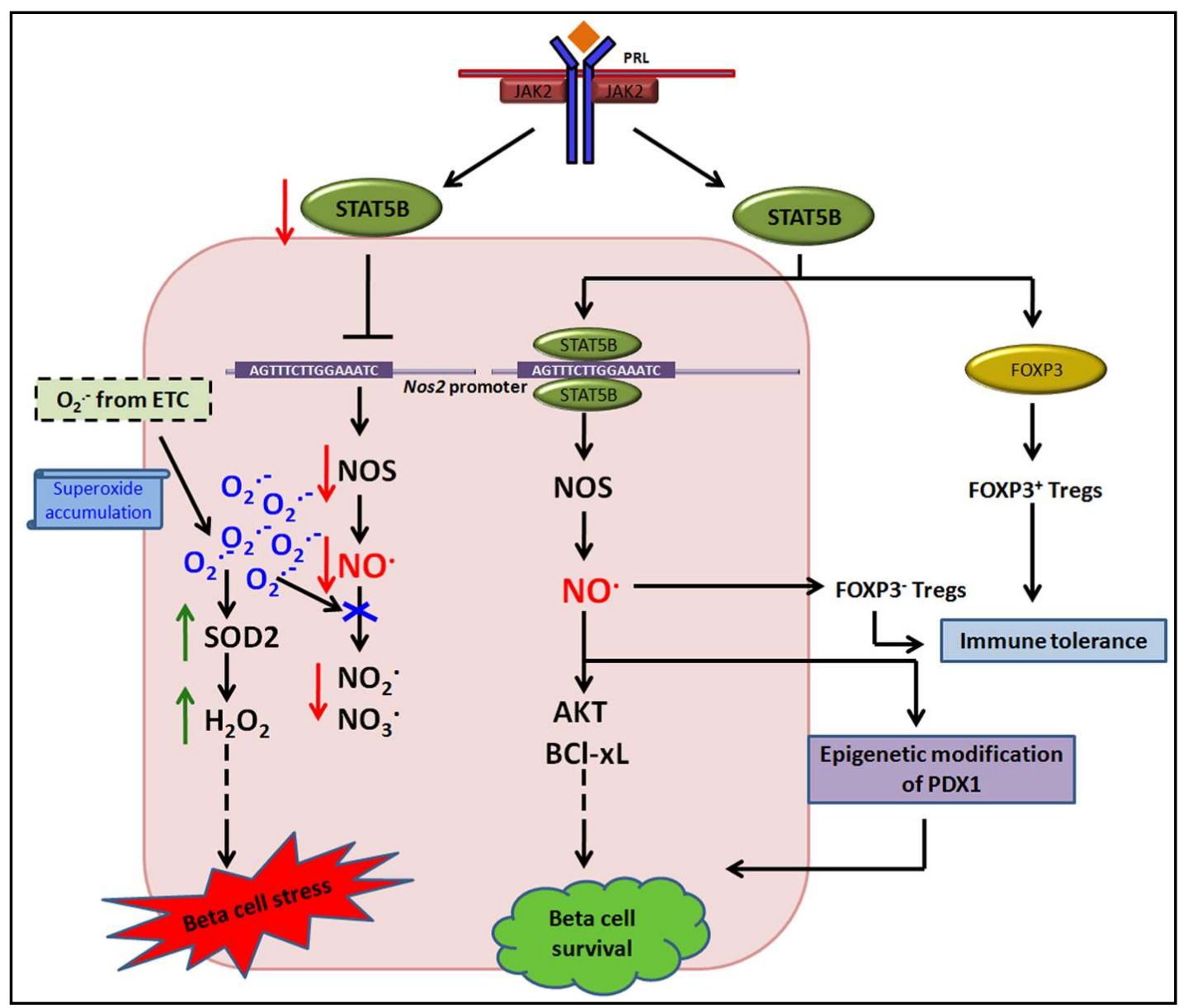

Fig. 6. Cartoon depicting the proposed role of STAT5B in regulation of oxidative stress in MIN6 $\beta$-cell line. The boxed area illustrates our hypothesis on regulation of nitric oxide by STAT5B. Binding of STAT5B to Nos2 promoter results in transcriptional activation of NOS2 and increased nitric oxide synthesis. This can augment prosurvival pathways by regulating AKT and BCL-xL expression and enables $\beta$-cell survival. This is in addition to the existing knowledge that STAT5B-regulated FOXP3+ T-regulatory cells (Tregs) and NOregulated FOXP3- Tregs promote immune tolerance, and nitric oxide can cause epigenetic modification of PDX1 enabling $\beta$-cell differentiation. When there is a dearth of STAT5B, Nos 2 activation is decreased with a diminished production of nitric oxide and its end products. At the same time, more superoxide anions from electron transport chain are available for SOD to be converted to $\mathrm{H}_{2} \mathrm{O}_{2}$. With no corresponding increase in $\mathrm{H}_{2} \mathrm{O}_{2}$ metabolizing enzymes, the surge in $\mathrm{H}_{2} \mathrm{O}_{2}$ results in $\beta$-cell stress.

\section{Conclusion}

Taken together, our results enable us to postulate that STAT5B is a key player in pancreatic $\beta$-cell maintenance. STAT5B upregulates Nos2 expression by binding to its promoter and this culminates in efficient removal of superoxide by $\mathrm{NO}$ produced thereby reducing the $\mathrm{H}_{2} \mathrm{O}_{2}$ load of $\beta$-cell which suffers from inapt $\mathrm{H}_{2} \mathrm{O}_{2}$ detoxification capacity. The reduced $\mathrm{H}_{2} \mathrm{O}_{2}$ load in $\beta$-cell under STAT5B signaling does not allow occurrence of oxidative stress. Reduced NO from physiological levels and increased superoxide and $\mathrm{H}_{2} \mathrm{O}_{2}$ levels under conditions of STAT5B insufficiency can cause decreased in Tregs on one hand, and decreased pro-survival molecule AKT on the other. The proposed involvement of STAT5B in the governance of oxidative stress important for $\beta$-cell maintenance is represented in Fig. 6. Thus transcriptional regulation of Nos2 by STAT5B in addition to its control of FOXP3 places STAT5B as a central figure responsible for $\beta$-cell maintenance and hence critical to protection from $\beta$-cell stress. 


\section{Cellular Physiology Cell Physiol Biochem 2018;52:141-155 \\ \begin{tabular}{l|l|l}
\hline DOI: 10.33594/000000010 & (c) 2019 The Author(s). Published by
\end{tabular} \\ and Biochemistry Published online: 18 February 2019 Cell Physiol Biochem Press GmbH\&Co. KG \\ Joseph et al:: STAT5B Activates Nos2 and Reins Oxidative Stress}

\section{Acknowledgements}

ML was supported by a Grant from Board of Research in Nuclear Sciences (BRNS) (\#37(1)/14/58/2014-BRNS/2180) and Rajiv Gandhi Centre for Biotechnology-Department of Biotechnology (RGCB-DBT) core funds. AJ was supported by a Research Fellowship from Council for Scientific and Industrial Research (09/716(0130)/2010-EMR-I), PLT by a Faculty Improvement program of University Grants Commission (FIP/12th Plan/KLMG026 TF-14), BSJ by a Research Fellowship from Department of Science \& Technology (DST/ INSPIRE Fellowship/2015/1F150361), RAP was supported by an Research Associateship from Science \& Engineering Research Board (SERB) DST (SB/SO/AS -016 / 2014) while LCR was supported by the BRNS grant.

ML was involved in project conception/supervision, experiment/Fig. 6 designing and manuscript review. AJ designed experiments/Fig. 6, executed experiments in Fig. 1-5, analyzed data, wrote manuscript. AJ, BSJ, RAP contributed to Fig. 1C. AJ, BSJ, PLT, LCR contributed to Fig. 2A and 5I. LCR and NP assisted AJ for Fig. 1E, 2B-C and 3.

\section{Disclosure Statement}

The authors declare no competing financial interests.

\section{References}

1 Gale EA: The discovery of type 1 diabetes. Diabetes 2001;50:217-226.

- 2 Kloppel G, Lohr M, Habich K, Oberholzer M, Heitz PU: Islet pathology and the pathogenesis of type 1 and type 2 diabetes mellitus revisited. Surv Synth Pathol Res 1985;4:110-125.

- 3 Thivolet C, Bendelac A, Bedossa P, Bach JF, Carnaud C: CD8+ T cell homing to the pancreas in the nonobese diabetic mouse is CD4+ T cell-dependent. J Immunol 1991;146:85-88.

4 Pesenacker AM, Wang AY, Singh A, Gillies J, Kim Y, Piccirillo CA, Nguyen ND, Haining WN, Tebbutt SJ, Panagiotopoulos C, Levings MK: A Regulatory T-Cell Gene Signature Is a Specific and Sensitive Biomarker to Identify Children With New-Onset Type 1 Diabetes. Diabetes 2016;65:1031-1039.

5 Serr I, Furst RW, Achenbach P, Scherm MG, Gokmen F, Haupt F, Sedlmeier EM, Knopff A, Shultz L, Willis RA, Ziegler AG, Daniel C: Type 1 diabetes vaccine candidates promote human Foxp3(+)Treg induction in humanized mice. Nat Commun 2016;7:10991.

6 Kanai T, Jenks J, Nadeau KC: The STAT5b Pathway Defect and Autoimmunity. Front Immunol 2012;3:234.

7 Murawski MR, Litherland SA, Clare-Salzler MJ, Davoodi-Semiromi A: Upregulation of Foxp3 expression in mouse and human Treg is IL-2/STAT5 dependent: implications for the NOD STAT5B mutation in diabetes pathogenesis. Ann N Y Acad Sci 2006;1079:198-204.

8 Davoodi-Semiromi A, Laloraya M, Kumar GP, Purohit S, Jha RK, She JX: A mutant Stat5b with weaker DNA binding affinity defines a key defective pathway in nonobese diabetic mice. J Biol Chem 2004;279:1155311561.

9 Jackerott M, Moldrup A, Thams P, Galsgaard ED, Knudsen J, Lee YC, Nielsen JH: STAT5 activity in pancreatic beta-cells influences the severity of diabetes in animal models of type 1 and 2 diabetes. Diabetes 2006;55:2705-2712.

10 Galsgaard ED, Nielsen JH, Moldrup A: Regulation of prolactin receptor (PRLR) gene expression in insulinproducing cells. Prolactin and growth hormone activate one of the rat prlr gene promoters via STAT5a and STAT5b. J Biol Chem 1999;274:18686-18692.

11 Padgett LE, Broniowska KA, Hansen PA, Corbett JA, Tse HM: The role of reactive oxygen species and proinflammatory cytokines in type 1 diabetes pathogenesis. Ann N Y Acad Sci 2013;1281:16-35.

12 Thayer TC, Delano M, Liu C, Chen J, Padgett LE, Tse HM, Annamali M, Piganelli JD, Moldawer LL, Mathews CE: Superoxide production by macrophages and T cells is critical for the induction of autoreactivity and type 1 diabetes. Diabetes 2011;60:2144-2151. 


\section{Cellular Physiology Cell Physiol Biochem 2018;52:141-155 \begin{tabular}{ll|l|l|l|l}
\hline DOI: 10.33594/000000010 & 2019 The Author(s). Published by
\end{tabular} and Biochemistry Published online: 18 February 2019 Cell Physiol Biochem Press GmbH\&Co. KG \\ Joseph et al.: STAT5B Activates Nos2 and Reins Oxidative Stress}

13 Nerup J, Mandrup-Poulsen T, Helqvist S, Andersen HU, Pociot F, Reimers JI, Cuartero BG, Karlsen AE, Bjerre U, Lorenzen T: On the pathogenesis of IDDM. Diabetologia 1994;37:S82-S89.

- 14 Pollock JS, Forstermann U, Tracey WR, Nakane M: Nitric oxide synthase isozymes antibodies. Histochem J 1995;27:738-744.

- 15 Takamura T, Kato I, Kimura N, Nakazawa T, Yonekura H, Takasawa S, Okamoto H: Transgenic mice overexpressing type 2 nitric-oxide synthase in pancreatic beta cells develop insulin-dependent diabetes without insulitis. J Biol Chem 1998;273:2493-2496.

- 16 Fatima N, Faisal SM, Zubair S, Ajmal M, Siddiqui SS, Moin S, Owais M: Role of Pro-Inflammatory Cytokines and Biochemical Markers in the Pathogenesis of Type 1 Diabetes: Correlation with Age and Glycemic Condition in Diabetic Human Subjects. PLoS One 2016;11:e0161548.

- 17 Corbett JA, Sweetland MA, Wang JL, Lancaster JR Jr., McDaniel ML: Nitric oxide mediates cytokine-induced inhibition of insulin secretion by human islets of Langerhans. Proc Natl Acad Sci U S A 1993;90:1731-1735.

18 Tessari P, Cecchet D, Cosma A, Vettore M, Coracina A, Millioni R, Iori E, Puricelli L, Avogaro A, Vedovato M: Nitric oxide synthesis is reduced in subjects with type 2 diabetes and nephropathy. Diabetes 2010;59:2152-2159.

- 19 Bagarolli RA, Saad MJ, Saad ST: Toll-like receptor 4 and inducible nitric oxide synthase gene polymorphisms are associated with Type 2 diabetes. J Diabetes Complications 2010;24:192-198.

- 20 Dogusan Z, Hooghe R, Verdood P, Hooghe-Peters EL: Cytokine-like effects of prolactin in human mononuclear and polymorphonuclear leukocytes. J Neuroimmunol 2001;120:58-66.

- 21 Møldrup A, Petersen ED, Nielsen JH: Effects of sex and pregnancy hormones on growth hormone and prolactin receptor gene expression in insulin-producing cells. Endocrinology 1993;133:1165-1172.

- 22 Caruso G, Fresta CG, Siegel JM, Wijesinghe MB, Lunte SM: Microchip electrophoresis with laser-induced fluorescence detection for the determination of the ratio of nitric oxide to superoxide production in macrophages during inflammation. Anal Bioanal Chem 2017;409:4529-4538.

23 de Campos RP, Siegel JM, Fresta CG, Caruso G, da Silva JA, Lunte SM: Indirect detection of superoxide in RAW 264.7 macrophage cells using microchip electrophoresis coupled to laser-induced fluorescence. Anal Bioanal Chem 2015;407:7003-7012.

24 Kent WJ, Sugnet CW, Furey TS, Roskin KM, Pringle TH, Zahler AM, Haussler D: The human genome browser at UCSC. Genome Res 2002;12:996-1006.

25 Gao J, Morrison DC, Parmely TJ, Russell SW, Murphy WJ: An interferon-gamma-activated site (GAS) is necessary for full expression of the mouse iNOS gene in response to interferon-gamma and lipopolysaccharide. J Biol Chem 1997;272:1226-1230.

26 Kojima H, Nakatsubo N, Kikuchi K, Kawahara S, Kirino Y, Nagoshi H, Hirata Y, Nagano T: Detection and imaging of nitric oxide with novel fluorescent indicators: diaminofluoresceins. Anal Chem 1998;70:24462453.

- 27 Kamijo R, Harada H, Matsuyama T, Bosland M, Gerecitano J, Shapiro D, Le J, Koh SI, Kimura T, Green SJ, et al.: Requirement for transcription factor IRF-1 in NO synthase induction in macrophages. Science 1994;263:1612-1615.

- 28 Dogusan Z, Hooghe R, Verdood P, Hooghe-Peters EL: Cytokine-like effects of prolactin in human mononuclear and polymorphonuclear leukocytes. J Neuroimmunol 2001;120:58-66.

29 Wink DA, Hines HB, Cheng RY, Switzer CH, Flores-Santana W, Vitek MP, Ridnour LA, Colton CA: Nitric oxide and redox mechanisms in the immune response. J Leukoc Biol 2011;89:873-891.

30 Niedbala W, Cai B, Liu H, Pitman N, Chang L, Liew FY: Nitric oxide induces CD4+CD25+ Foxp3 regulatory T cells from CD4+CD25 T cells via p53, IL-2, and OX40. Proc Natl Acad Sci U S A 2007;104:15478-15483.

31 Shiekh GA, Ayub T, Khan SN, Dar R, Andrabi KI: Reduced nitrate level in individuals with hypertension and diabetes. J Cardiovasc Dis Res 2011;2:172-176.

32 Liu D, Pavlovic D, Chen MC, Flodstrom M, Sandler S, Eizirik DL: Cytokines induce apoptosis in betacells isolated from mice lacking the inducible isoform of nitric oxide synthase (iNOS-/-). Diabetes 2000;49:1116-1122.

- 33 Douguet L, Cherfils-Vicini J, Bod L, Lengagne R, Gilson E, Prevost-Blondel A: Nitric Oxide Synthase 2 Improves Proliferation and Glycolysis of Peripheral gammadelta T Cells. PLoS One 2016;11:e0165639.

- 34 Niedbala W, Besnard AG, Nascimento DC, Donate PB, Sonego F, Yip E, Guabiraba R, Chang HD, Fukada SY, Salmond RJ, Schmitt E, Bopp T, Ryffel B, Liew FY: Nitric oxide enhances Th9 cell differentiation and airway inflammation. Nat Commun 2014;5:4575. 


\section{Cellular Physiology Cell Physiol Biochem 2018;52:141-155

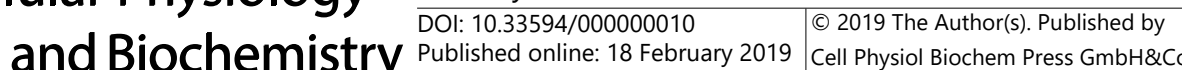

35 Beckman JS, Koppenol WH: Nitric oxide, superoxide, and peroxynitrite: the good, the bad, and ugly. Am J Physiol 1996;271:C1424-C1437.

36 Lenzen S, Drinkgern J, Tiedge M: Low antioxidant enzyme gene expression in pancreatic islets compared with various other mouse tissues. Free Radic Biol Med 1996;20:463-466.

- 37 Tiedge M, Lortz S, Drinkgern S, Lenzen S: Relation between antioxidant enzyme gene expression and antioxidative defense status of insulin-producing cells. Diabetes 1997;46:1733-1742.

38 Gheysarzadeh A, Yazdanparast R: STAT5 reactivation by catechin modulates H20 2-induced apoptosis through miR-182/FOXO1 pathway in SK-N-MC cells. Cell Biochem Biophys 2015;71:649-656.

39 Fujinaka Y, Takane K, Yamashita H, Vasavada RC: Lactogens promote beta cell survival through JAK2/STAT5 activation and Bcl-XL upregulation. J Biol Chem 2007;282:30707-30717.

40 Creamer BA, Sakamoto K, Schmidt JW, Triplett AA, Moriggl R, Wagner KU: Stat5 promotes survival of mammary epithelial cells through transcriptional activation of a distinct promoter in Akt1. Mol Cell Biol 2010;30:2957-2970.

41 Tejedo JR, Cahuana GM, Ramirez R, Esbert M, Jimenez J, Sobrino F, Bedoya FJ: nitric oxide triggers the phosphatidylinositol 3-kinase/Akt survival pathway in insulin-producing RINm5F cells by arousing Src to activate insulin receptor substrate-1. Endocrinology 2004;145:2319-2327.

- 42 Mejia-Garcia TA, Portugal CC, Encarnacao TG, Prado MA, Paes-de-Carvalho R: Nitric oxide regulates AKT phosphorylation and nuclear translocation in cultured retinal cells. Cell Signal 2013;25:2424-2439.

- 43 Salguero-Aranda C, Tapia-Limonchi R, Cahuana GM, Hitos AB, Diaz I, Hmadcha A, Fraga M, Martin F, Soria B, Tejedo JR, Bedoya FJ: Differentiation of Mouse Embryonic Stem Cells Towards Functional Pancreatic BetaCell Surrogates through Epigenetic Regulation of Pdx1 by Nitric Oxide. Cell Transplant 2016;25:1879-1892. 